Document downloaded from:

http://hdl.handle.net/10251/140977

This paper must be cited as:

Masip, X.; Cazorla-Marín, A.; Montagud- Montalvá, C.; Marchante-Avellaneda, J.; Barceló Ruescas, F.; Corberán, JM. (08-2). Energy and techno-economic assessment of the effect of the coupling between an air source heat pump and the storage tank for sanitary hot water production. Applied Thermal Engineering. 159(113853):1-8.

https://doi.org/10.1016/j.applthermaleng.2019.113853

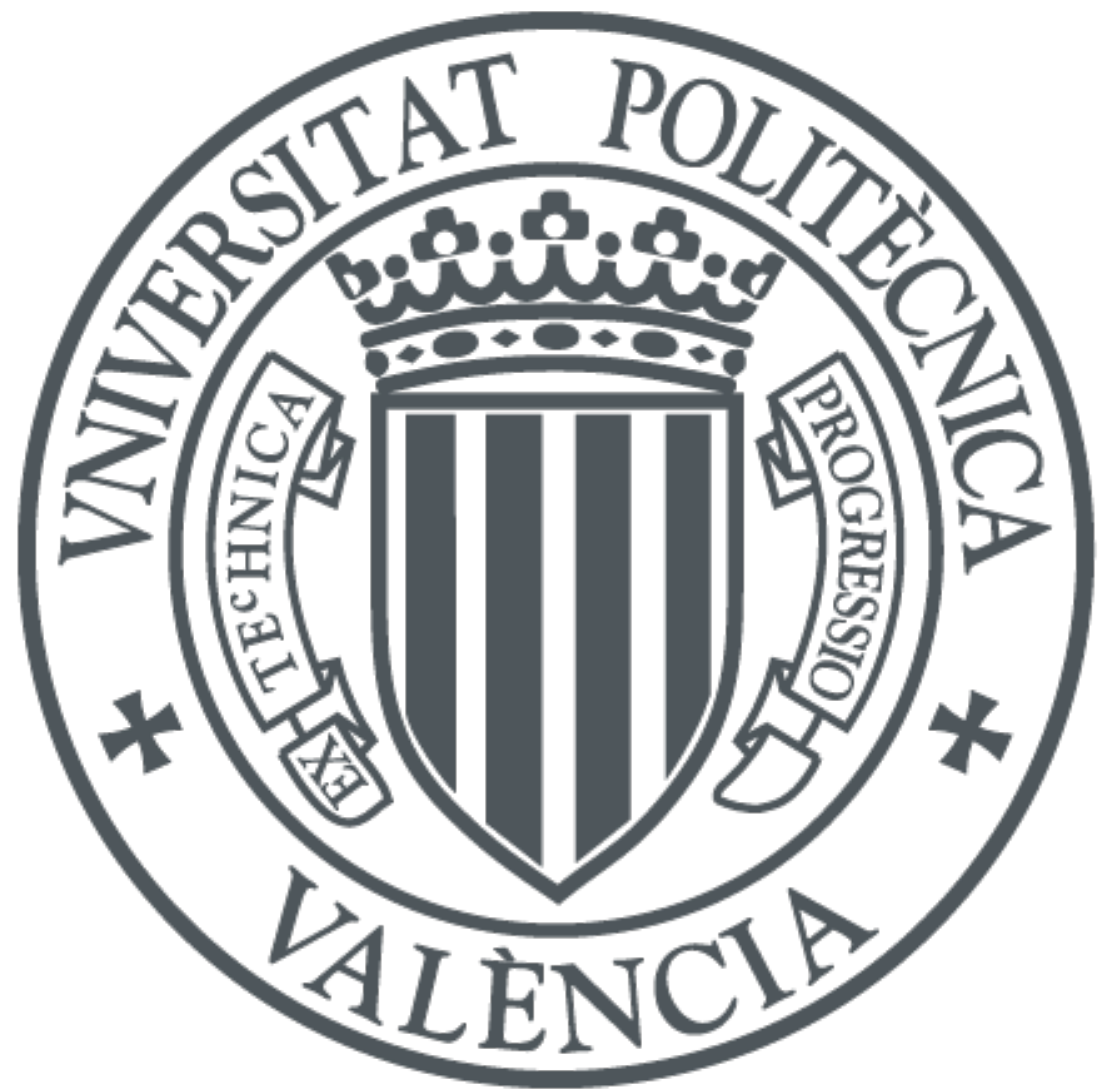

The final publication is available at

https://doi.org/10.1016/j.applthermaleng.2019.113853

Copyright Elsevier

Additional Information 


\title{
ENERGY AND TECHNO-ECONOMIC ASSESSMENT OF THE EFFECT OF THE COUPLING BETWEEN AN AIR SOURCE HEAT PUMP AND THE STORAGE TANK FOR SANITARY HOT WATER PRODUCTION
}

\author{
X. Masip*, A. Cazorla-Marín, C. Montagud, J. Marchante, J.M. Corberán \\ Instituto Universitario de Investigación de Ingeniería Energética (IUIIE), \\ Universitat Politècnica de València, Valencia, 46022, Spain. \\ e-mail:xmasip@iie.upv.es web: http://www.iie.upv.es
}

\begin{abstract}
:
Heat pumps are proved to be a highly efficient technology for sanitary hot water production. Particularly, in the case of air source heat pumps, a strong effort has been dedicated to improve their efficiency. However, when installing those highly efficient heat pumps coupled with the storage tank needed for sanitary hot water production, an inefficiency is introduced in the system since this coupling has to be indirect according to EN 1717:2000 to prevent from any potential pollution of potable water in case of a leakage of refrigerant into the tank. In practice, there are only three options for this coupling: through a coil heat exchanger inside the tank, an intermediate heat exchanger between the tank and the heat pump or a double wall condenser. The objective of this research work thus is to determine the indirect coupling with the highest energy efficiency, cost-effectiveness and the lowest environmental impact.

The results show that this indirect coupling could lead up to a $30 \%$ global efficiency reduction. In this report, a techno-economic evaluation was carried out for the representative climate conditions around Europe, resulting in the double wall condenser type of coupling as the most efficient, cost-effective and least $\mathrm{CO}_{2}$ emitter option for all the cases analysed.
\end{abstract}

Keywords: heat pump; energy efficiency; sanitary hot water production; thermal energy storage; energy optimization; techno-economic assessment 


\section{Introduction}

The importance of the energy usage in buildings is undeniable, being currently responsible of the $40 \%$ of the energy consumption and $36 \%$ of $\mathrm{CO}_{2}$ emissions in Europe, as stated in [1]. Analysing concretely the case of households, according to [2], the gross of the energy consumption corresponds to space heating $(64.7 \%)$ and water heating systems ( $14.5 \%)$. In this context, the 2010 Energy Performance of Buildings Directive (EPBD) came into force introducing for the first time the concept of Near Zero Energy Building (NZEB) and with the objective of considerably reducing the energy demand of this sector, contributing thus to the future decarbonization of Europe according to H2O2O targets.

Considering the NZEB aspect in the near future, the energy consumption percentage dedicated to space heating will be highly reduced and then the energy consumption for sanitary hot water production (SHW) will even represent a higher percentage. As a consequence, the reduction of the latter will play an important role in the objective of reducing the total energy demand in the residential sector and its associated $\mathrm{CO}_{2}$ emissions. Differently to the space heating consumption, the energy consumption of the system dedicated to SHW production cannot be reduced just by acting on the demand without the risk of not satisfying the user comfort. Therefore, in order to reduce the system energy consumption, it will be key the use of highly energy efficient technologies, such as Heat Pump (HP) systems that are recognized as a renewable energy resource by the European Directive 2009/28/CE [3].

However, in the case of SHW production, the HP is just one of the components of the integrated system. In fact, it is coupled to the SHW storage tank. So, in order to optimize the system energy performance, not only the heat pump must be efficient but also the design and operation of the integrated SHW system.

HP technology presents at this moment a remarkably high efficiency itself, with a strong research and development effort dedicated over the last and current years to further increasing it, as stated in [4], [5]. However, not so many studies were found in literature addressing the effects of the design and/or operation of the other system components existing in an installation for SHW production in the system global efficiency.

Considering the whole system, it is undeniable the high importance and contribution of the thermal energy storage (TES) system to the global efficiency, as stated in [6], [7]. Several studies have been carried out focusing on the thermal stratification within the storage tank and analyzing its influence on the system energy efficiency [8]-[11]. Apart from the thermal stratification and according to [10], the performance of those systems combining a HP and a storage tank is usually lower than the one expected. This fact is often due to the hydraulic integration of the system. Various studies, such as [6], [10], [12], study the influence of the hydraulic integration on the system global efficiency. Finally, the control of the facility plays a key role on the global efficiency, as described in [6], [7], [10], [13], [14], in which different control strategies to optimize the system energy performance are assessed.

However, there is a lack of studies about the kind of coupling employed between the HP and the storage tank which, according to EN 1717:2000, is of compulsory fulfillment in order to prevent potential pollution of potable water by a refrigerant leakage to water in the condenser. Special attention must be paid to this indirect coupling, as it has a negative effect on the system global efficiency, with a system energy efficiency reduction that can reach values up to $30 \%$, depending on the type of coupling as it has been found in this study. The aim of this research work is to compare the system energy performance, cost-effectiveness and environmental cost (in terms 
of $\mathrm{CO}_{2}$ emissions) of three different possible types of coupling between the HP and the TES system for SHW production: coil heat exchanger inside the storage tank, brazed plate heat exchanger outside the tank with a double water loop, and double wall heat pump condenser. Studies were carried out taking as a reference the direct coupling option, which corresponds to that when the water inside the TES is the secondary fluid at the HP condenser.

This paper presents the results of the energy and techno-economic assessment of the effect of the coupling between an air source heat pump (ASHP) and the storage tank for SHW production. First, each of the different types of coupling analyzed is introduced. Then, the developed system model in TRNSYS and the optimization process is described in detail. Finally, the results of the energy optimization, the techno-economic and environmental assessment are presented with the aim to identify the case with the highest energy efficiency, the highest cost-effectiveness and the lowest environmental cost for the different representative climates in Europe. The HP cases are compared with one of the most conventional ways of producing SHW, an immersed electric heater. The gas boiler case, which is together with the immersion electric heater one of the most conventional ways of producing SHW, has been discarded from the study since we aimed at decarbonized technologies only.

\section{System description}

\subsection{Cases analyzed}

In Fig. 1 the three possible coupling options between the HP and the TES are shown. Fig. 1a represents the Base Case (BC), considered as a reference for the studies. This $B C$ corresponds to the direct coupling case that would not fulfil the European Norm EN-1717:2000, since the secondary fluid (water) exiting the HP condenser is the same as the one entering the tank, putting in potential contact the refrigerant with the potable water that might be polluted in case of a refrigerant leakage [15]. Although this case does not comply with the norm, it has been considered as the base case since it is the optimal from the thermodynamics point of view, keeping the stratification in the TES as much as possible and keeping to the minimum the temperature difference between the condensation and the tank temperature.

Fig. $1 \mathrm{~b}$ shows the Coil Case (CC). In this case, the coupling between the HP and the storage tank is made by means of a coil heat exchanger inside the tank fulfilling thus with the EN-1717:2000, since any refrigerant leakage will remain in the secondary fluid loop and will not reach the interior of the tank. The fluid circulating through the coil is the secondary fluid of the HP condenser (water).

The External Heat Exchanger Case (EHXC) consists of inserting an intermediate closed water loop connected to the condenser and to a brazed plate heat exchanger (BPHE) which transfers the heat to another water loop with direct coupling to the TES. This coupling strategy requires one extra circulation pump and an intermediate BPHE. A sketch of the EHXC is shown in Fig 1c.

The Double Wall Condenser Case (DWCC) (sketched in Fig. 1d) is almost equal to the BC, but in this case, the condenser of the HP is a double wall condenser, which separates the refrigerant from the water through a very thin air gap in a way that the refrigerant could never leak into the water. The double wall condenser, however, introduces an inefficiency in the heat exchange process in the condenser. 


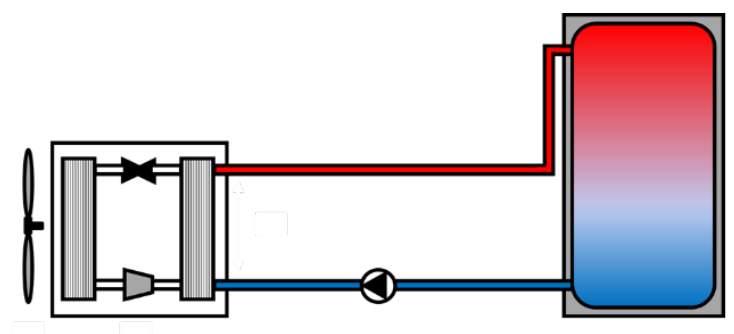

a) BASE CASE

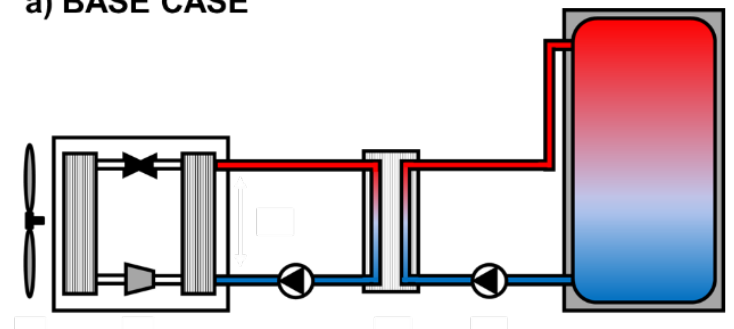

c) EXTERNAL HEAT EXCHANGER CASE

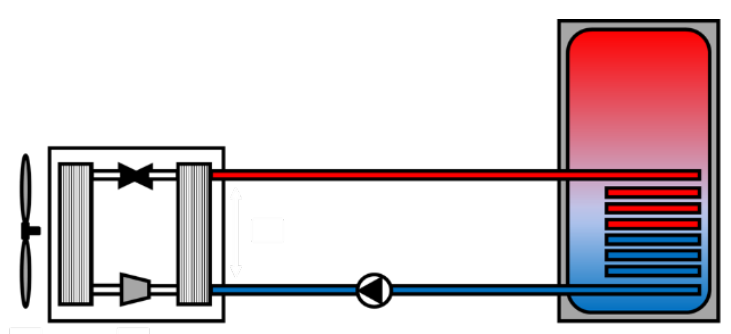

b) COIL CASE

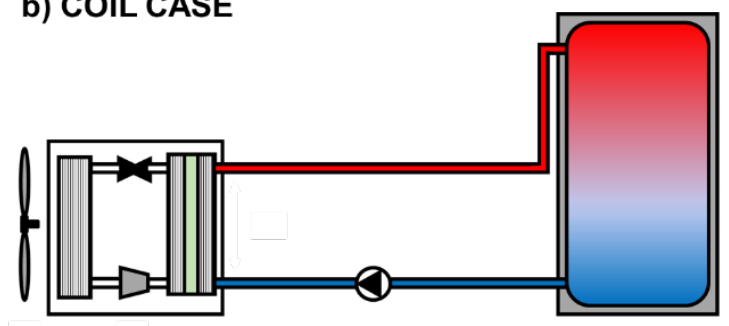

d) DOUBLE WALL CONDENSER CASE

Fig. 1. Sketch of the different coupling options presented: a) Base Case, b) Coil Case, c) External Heat Exchanger Case and d) Double Wall Condenser Case.

\subsection{Components modelling}

TRNSYS [16] has been the simulation tool used to model and analyse the different cases presented. An integrated system model was created in TRNSYS. The main components of the model are: the HP, the storage tank, the BPHE (only for the EHXC) and the control.

The HP considered is an ASHP which was developed, experimentally tested and fully characterised in the framework of a H2020 European project named Geot€ch [17]. The HP operates with R32 as refrigerant with a nominal capacity of $8 \mathrm{~kW}$. It is a variable capacity HP (inverter compressor) designed to provide heating, cooling and SHW. Its performance is modeled as a black box by implementing polynomial correlations, which were obtained from the experimental testing campaign, in a new TRNSYS type. The polynomial correlations implemented in the new TRNSYS type are presented in Fig. 2, in which the comparison between the experimental results and the ones obtained with the correlations are compared. Further details are provided in [18], [19]. This work will only be focused on the SHW production mode.

Qc (W)

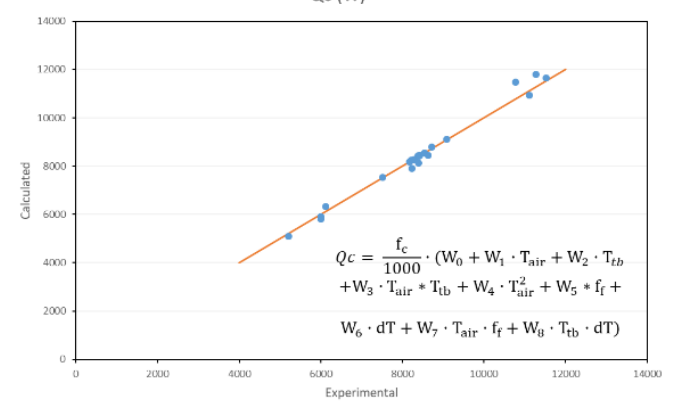

Wc (W)

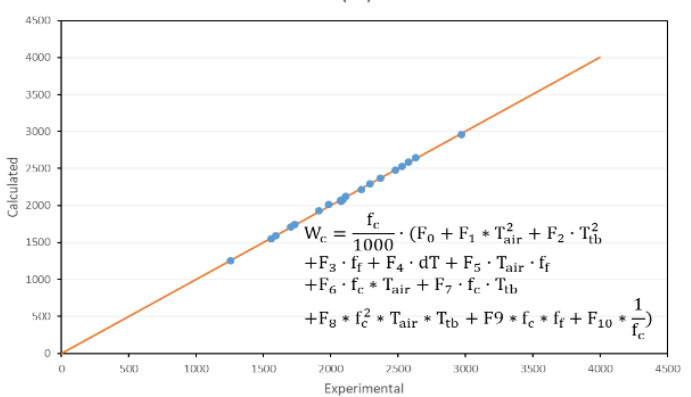

Fig. 2. Equations implemented in the model versus experimental results.

The TES system has been simulated with TRNSYS type 60 because it is "the most detailed tank model available in the standard TRNSYS library" according to TRNSYS user manual and mathematical reference, and also because it has been widely used and experimentally validated in previous research publications such as [20]. The storage tank considered in the model is a 
commercial one, concretely WOLF's SE-2 model of 200 liters, that is the usual value for the demand considered (single family house in Europe), and with the possibility to integrate a coil inside.

The BPHE considered in the model is also a commercial one, concretely SWEP's B16 model. It was also modelled in TRNSYS in terms of UA-Value and pressure drop as a function of the number of plates and mass flow rates. This way, during the optimization process, the total number of plates could be obtained as the one that makes the global system energy performance maximum at a reasonable cost. The UA-Value and pressure drop correlations as well as the determination of the total number of plates considered is deeply explained in [21].

Regarding the Double Wall Condenser Case, it was necessary to make a new correlation for the HP model, since it introduces a penalty on the condenser performance. The equivalent thermal conductivity of the double plate separating two refrigerant channels $\left(k^{\prime}\right)$ is obtained departing from an apparent fouling factor $(\beta)$ provided by the manufacturer [22] which takes into account the resistance of the air gap in between the double plates. Once this new effective thermal conductivity was estimated, the new HP performance correlations were obtained in IMST-ART software [23] and the HP model was updated in the corresponding TRNSYS type.

$$
\frac{e}{k}+\beta=\frac{e}{k^{\prime}} \rightarrow k^{\prime}=\frac{e}{\frac{e}{k}+\beta}
$$

Finally, regarding the control of the system, it was found that in order to make a fair comparison, it must be guaranteed that the thermal energy stored in the tank $(\mathrm{kWh})$ is the same in all cases considered. This way, the control was programmed to handle the average temperature in the tank to a value equal to $45^{\circ} \mathrm{C}$. This way, it is possible to guarantee that, once charged, the thermal energy stored in the tank is the same in all the simulations carried out. This study has been performed for an average final tank temperature of $45^{\circ} \mathrm{C}$ because it was part of a study trying to keep the SHW temperature as low as possible. Anyhow, the main conclusions of the study are independent of the final temperature, being of general application. The legionella problem will be solved with periodic chemical treatments within the water tank, allowing thus the system to work at $45^{\circ} \mathrm{C}$. As it is a small system, there is no recirculation of the water, thus it is excluded from the risk facilities according to the drinking water directive [24].

\subsection{Integrated system model}

The study will be carried out for three European locations: Athens, Strasbourg and Helsinki, which have strategically been selected in order to stand for the climate diversity in Europe according to the energy labeling normative [25]. The aim of proceeding this way is to obtain the optimal design and operating conditions for the entire Eurozone.

The present study is focused only on the charging process, in this way it will be simulated one typical day for summer (TDS) and for winter (TDW) for each one of the selected locations. The two typical days in each region were selected in such a way that the mean temperature of the day (MTD) was the closest to the mean temperature of the season (MTS) considered, and that the temperature evolution during the day followed a typical smooth sinusoidal evolution. Table 1 shows the typical days selected for summer and winter operation, as well as the tap water (Ttap) temperature considered for each case. 


\begin{tabular}{cccc}
\hline & ATHENS & STRASBOURG & HELSINKI \\
\hline TDS & 30th July & 21st June & 30th June \\
TDW & 3rd February & 4th March & 29th December \\
MTS-Summer & 26.09 & 17.94 & 14.92 \\
MTD-Summer & 26.09 & 17.93 & 14.93 \\
MTS-Winter & 9.65 & 1.67 & -6.77 \\
MTD-Winter & 9.68 & 1.68 & -6.82 \\
Ttap summer (C) & 19.62 & 13.40 & 10.46 \\
Ttap winter (C) & 10.62 & 5.29 & 5.11 \\
\hline
\end{tabular}

Table 1. Typical day and tap water temperature values considered.

The integrated system model considered, consists of a multi-variable air source heat pump system where not only the frequency of the heat pump compressor can vary but also the frequency of the fan and the water circulation pumps (variable temperature difference in the heat exchangers). Fig. 3 shows the variables considered for the optimization study: frequency of the compressor ( $\mathrm{fc}$ ), frequency of the fan ( $\mathrm{ff}$ ) and the temperature difference of the secondary fluid in the condenser (dTc). In the case of the EHXC, two additional optimization variables were considered: the number of plates $(\mathrm{Np})$ and the secondary mass flow rate circulating in between the BPHE (m2) and the tank, expressed as a function of the primary mass flow rate in the BPHE (m1).

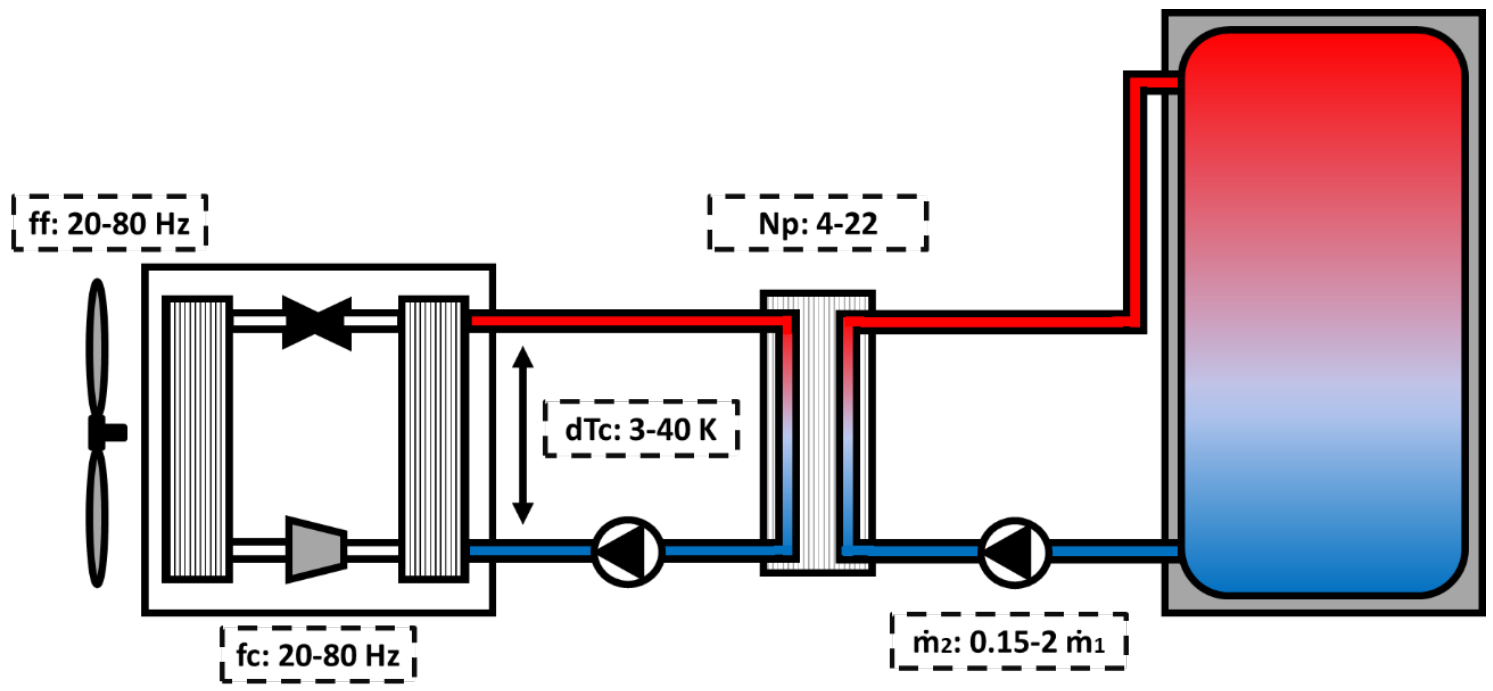

Fig. 3. Variables and range considered for the optimization of the multivariable model.

\section{Analysis methodology}

\subsection{Energy performance assessment}

The aim of the energy performance assessment is to determine the optimal system global efficiency for each type of coupling, location and season considered. First, a sensitivity analysis was performed by means of TRNSYS TRNEDIT parametric tool [16], in order to analyse the isolated effect of each of the variables on the system global efficiency. Then, the TRNSYS TRNOPT optimization tool [16] was used to determine, for each case, the values of the variables that make the system work on its optimal point (maximum efficiency). 
The Seasonal Performance Factor (SPF) was chosen as the indicator to assess the energy performance of the system. Concretely, the SPF4 defined in the SEPEMO-build project [26] was selected, since it settles a common and "defined methodology for calculation of the seasonal performance factor and a definition of which devices of the system have to be included in this calculation" [45]. Eq. (2) introduces the expression considered for SPF4.

$$
S P F_{4}=\frac{Q_{W_{-} h p}+Q_{W_{-} b u}}{E_{B_{-} \text {pump }}+E_{S_{-f a n}}+E_{W_{h p}}+E_{W_{-} b u}}
$$

Where $Q$ is the useful heat, provided from the HP $\left(Q_{W_{-} h p}\right)$ or the back-up system $\left(Q_{W_{-} b u}\right)$ and $\mathrm{E}$ is the power consumption of each of the components present in the system: compressor $\left(E_{W_{-} h p}\right)$, fan $\left(E_{S_{-f a n}}\right)$, external circulation pump/s $\left(E_{B_{-} \text {pump }}\right)$ and back-up system $\left(E_{W_{-} b u}\right)$.

Finally, but not less important, the user comfort has to be guaranteed. For this purpose, the lowest SHW temperature delivered to the user was settled at $35{ }^{\circ} \mathrm{C}$, and a restriction was imposed to the model which consists of having a minimum comfort factor of $95 \%$ from 8 am to $9 \mathrm{pm}$, otherwise the case is rejected. The comfort factor is calculated according to Eq. (3).

$$
\text { Comfort }_{\text {factor }}=\frac{\int \dot{m}_{\text {Tsup } \geq 35}}{\int \dot{m}_{\text {TOTAL }}} \quad \text { if } 8 \text { am }<t<9 \mathrm{pm}
$$

Where $\dot{m}_{\text {Tsup } \geq 35}$ is the supplied mass flow rate of the system at a temperature higher than $35^{\circ} \mathrm{C}$ and $\dot{m}_{\text {Total }}$ is the total demanded mass flow rate from the user, both considered in the same time frame (from 8 am to $9 \mathrm{pm}$ ).

\subsection{Techno-economic and environmental assessment}

A techno-economic study is essential to determine the best option available in the market, in economic terms. The energy analysis determines the most energy efficient case, but it does not take into consideration the different system costs. By undertaking a techno-economic study, not only the energy efficiency of the system is considered, but also the system, annual and investment costs. Three economic indicators were considered in the assessment: the Net Present Value (NPV), the Payback period (PB) and the Internal Rate of Return (IRR).

Additionally, the impact of each case on the environment will be analysed including an environmental assessment. The $\mathrm{CO}_{2}$ emission intensities considered for the study, shown in Table 2, were obtained from the European Environment Agency (EEA) [27].

In order to accurately perform the techno-economic study, several key parameters need to be defined: the interest market rate, the inflation rate, the useful life of the facility and obviously the system costs. The values considered for each of the parameters are shown in Table 2 . The market interest rate, the inflation rate and the electricity prices, were obtained from the Eurostat database [28], calculated as the mean value for the last five years (2017-2013). According to usual practice, the useful life of the facility considered is 15 years. 


\begin{tabular}{cccccc}
\hline & & GREECE & FRANCE & FINLAND & EU28 \\
\hline $\begin{array}{c}\text { CO2 emission } \\
\text { intensities } \\
\begin{array}{c}\text { Electricity } \\
\text { price }\end{array}\end{array}$ & gCO2/kWh & 829.9 & 34.80 & 106.40 & 275.90 \\
Gas price & $€ / \mathrm{kWh}$ & 0.23 & 0.28 & 0.31 & 0.32 \\
$\begin{array}{c}\text { Inflation rate } \\
\text { Interest }\end{array}$ & $\%$ & $-0.44 \%$ & $0.63 \%$ & $0.90 \%$ & $0.72 \%$ \\
market rate & $\%$ & $6.11 \%$ & $2.40 \%$ & $2.67 \%$ & $2.50 \%$ \\
\hline Table 2. Parameters for the techno-economic and environmental assessment [27], [28].
\end{tabular}

Finally, regarding the system costs, the following were identified: initial investment cost, annual costs and savings costs. The annual costs were calculated using TRNSYS with an annual simulation for each of the cases considered. With this objective, a single-family of 3 people demand profile has been used, obtained with DHWcalc software [29] and shown in Fig. 4. Regarding the saving costs, they were calculated comparing the heat pump case with the electric immersion heater. Concerning the electricity price, three scenarios were considered: the scenario 1 with the average electricity prices for the last five years, the scenario 2 considering a $10 \%$ increase of the average electricity price without taxes, and the scenario 3 considering a $10 \%$ reduction of the average electricity price without taxes. In this report, results for the scenario 3 are presented, since it is the scenario with the minimum profitability for the HP technology. Furthermore, it has been considered as the most realistic case in the coming future due to the growing of renewable energies in the market. Finally, regarding the investment costs, a detailed budget for each of the cases considered was obtained according to manufacturer prices. The budget details can be found in the Appendix.

\section{Annual demand profile}

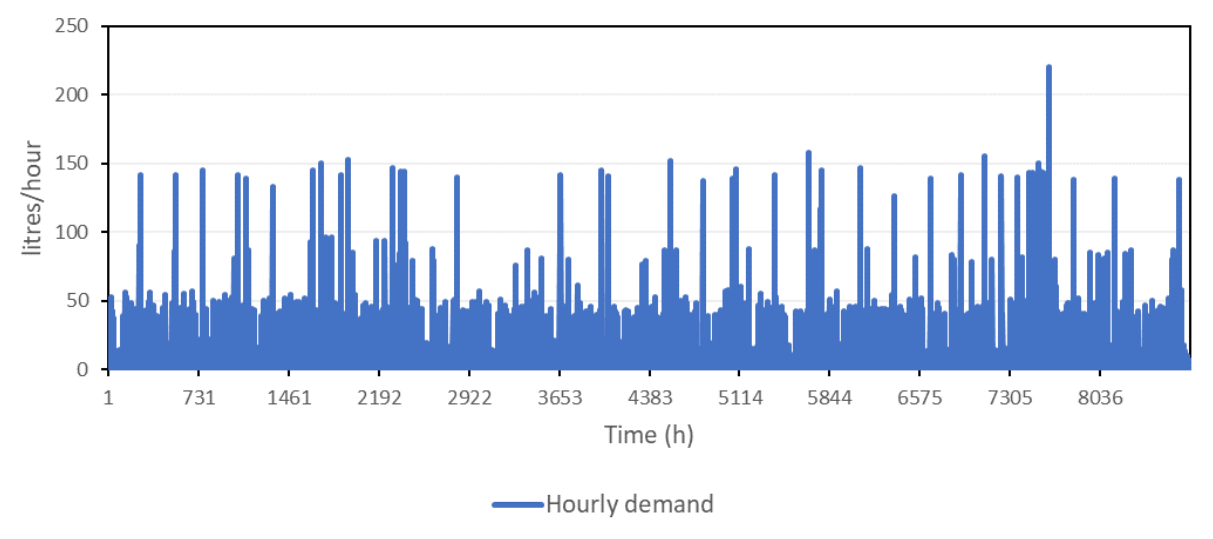

Fig. 4. Annual demand profile for the techno-economic study [29]. 


\section{Results and discussion}

\subsection{Optimization results}

SPF4 represents the global efficiency of the system, so it includes the energy consumption of all the components existing in the system: compressor, circulation pumps, fan and parasitic losses according to SEPEMO's definition in Eq. (2).

\begin{tabular}{cccccccccccc}
\hline \multirow{2}{*}{ Location } & \multicolumn{4}{c}{ Case } & \multicolumn{2}{c}{$\mathbf{f f}(\mathbf{H z})$} & \multicolumn{2}{c}{$\mathbf{f c}(\mathbf{H z})$} & \multicolumn{2}{c}{ dTc (K) } & \multicolumn{2}{c}{ m1/m2 (-) } & \multicolumn{2}{c}{ Np (-) } \\
& & Winter & Summer & Winter & Summer & Winter & Summer & Winter & Summer & Winter & Summer \\
\hline \multirow{4}{*}{ HEL } & BC & 20.6 & 20.625 & 80.0 & 48.125 & 3.0 & 3.375 & - & - & - & - \\
& CC & 25.6 & 21.25 & 41.3 & 33.75 & 3.0 & 3 & - & - & - & - \\
& EHXC & 20.0 & 20 & 80.0 & 37.5 & 3.0 & 3 & 0.8 & 0.775 & 22.0 & 22 \\
& DWCC & 20.6 & 20 & 80.0 & 45 & 3.0 & 3 & - & - & - & - \\
\hline \multirow{4}{*}{ STR } & BC & 20.6 & 20 & 80.0 & 48.75 & 3.2 & 3.3125 & - & - & - & - \\
& CC & 25.0 & 20 & 41.3 & 48.75 & 3.0 & 3.3125 & - & - & - & - \\
& EHXC & 20.0 & 21.25 & 80.0 & 38.125 & 3.1 & 3.125 & 0.7 & 0.8125 & 22.0 & 22 \\
& DWCC & 20.0 & 20 & 80.0 & 45.3125 & 3.3 & 3.25 & - & - & - & - \\
\hline \multirow{4}{*}{ ATH } & BC & 20.0 & 20 & 80.0 & 48.75 & 3.4 & 3.3125 & - & - & - & - \\
& CC & 21.3 & 20 & 37.5 & 32.1875 & 3.0 & 3.375 & - & - & - & - \\
& EHXC & 22.5 & 20 & 41.3 & 38.125 & 3.1 & 3.4375 & 0.9 & 0.8 & 22.0 & 22 \\
& DWCC & 20.6 & 20 & 49.4 & 43.75 & 3.0 & 3.8125 & - & - & - & - \\
\hline
\end{tabular}

Table 3. Variables values for the optimal value of SPF4 in summer and Winter, for each location and case analysed.

Fig. 5 and Fig. 6 show the maximum values of the SPF4 achieved as a result of the energy optimization for the different selected locations for the typical days simulated in winter and summer respectively. Each of the cases included has been previously simulated in order to obtain the variable values that make maximum the SPF4 of each case independently. Thus, the different cases are compared for their optimal working conditions, with the values of $f c, f f, d T c$, $N p$ and $\dot{m} 2 / \dot{m} 1$ that maximize their global efficiency of the system, which analysis can be consulted in [30] and their values in Table 3.

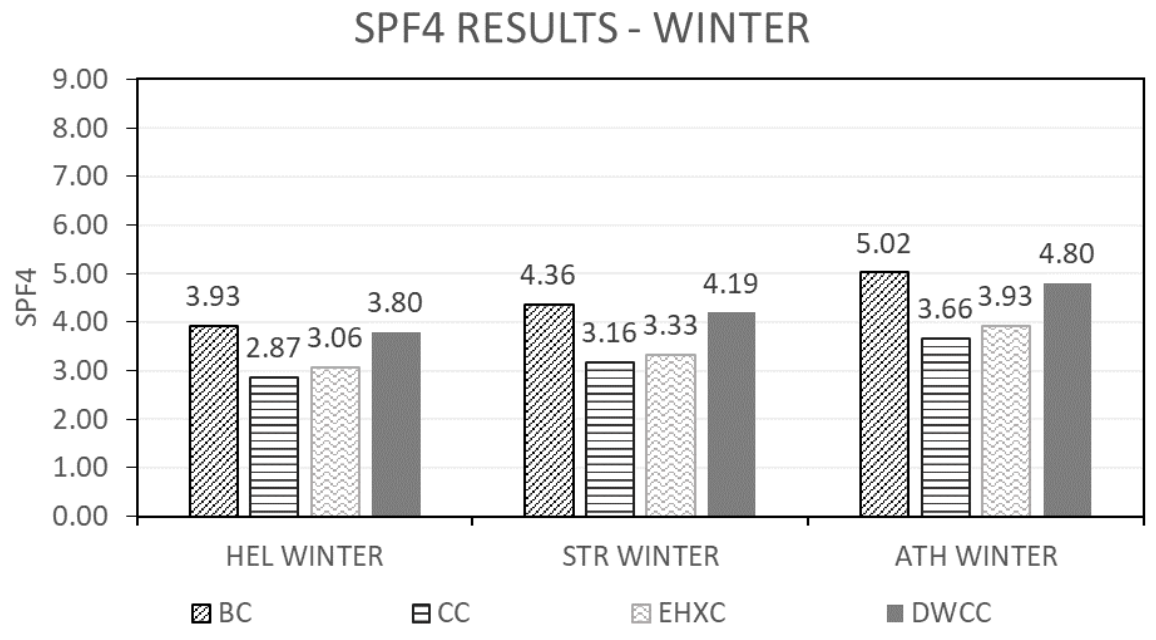

Fig. 5. SPF4 results for winter. 


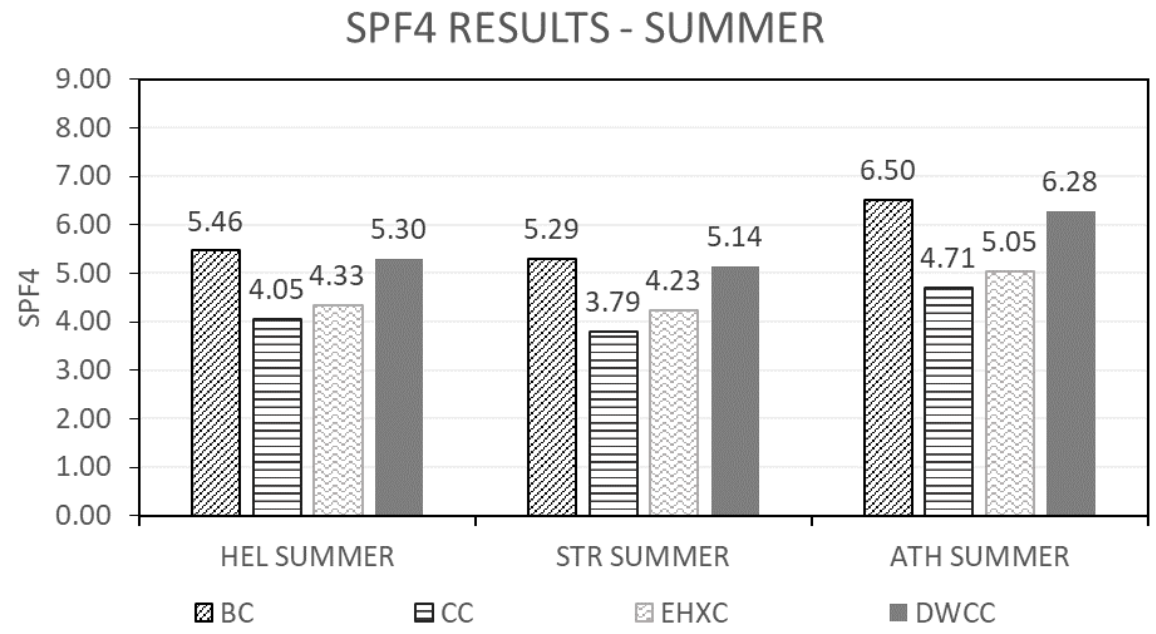

Fig. 6. SPF4 results for summer.

As expected, the direct coupling between the HP and the storage tank (BC) reaches always the highest energy efficiency in all the cases analysed due to the lack of energy losses caused by the presence of an intermediate heat exchanger ( $C C$ and EHXC) or a lower heat transfer efficiency in the condenser (DWCC). Taking the BC as the reference case, Table 4 presents the percentage reduction in the SPF4 for each type of tank coupling analysed with respect to the BC.

\begin{tabular}{ccccccc}
\hline \multicolumn{7}{c}{ SPF4 } \\
\hline & HEL & HEL & STR & STR & ATH & ATH \\
& WINTER & SUMMER & WINTER & SUMMER & WINTER & SUMMER \\
\hline BC & $0.00 \%$ & $0.00 \%$ & $0.00 \%$ & $0.00 \%$ & $0.00 \%$ & $0.00 \%$ \\
CC & $26.97 \%$ & $25.97 \%$ & $27.40 \%$ & $28.38 \%$ & $26.99 \%$ & $27.59 \%$ \\
EHXC & $22.14 \%$ & $20.74 \%$ & $23.49 \%$ & $20.15 \%$ & $21.72 \%$ & $22.40 \%$ \\
DWCC & $3.27 \%$ & $3.06 \%$ & $3.80 \%$ & $2.82 \%$ & $4.45 \%$ & $3.48 \%$ \\
\hline Table 4. Percentage reduction of SPF4 for each type of tank coupling with respect to the BC.
\end{tabular}

As it can be observed, the DWCC is the most efficient type of indirect coupling with a $3.66 \%$ average reduction when compared to the direct coupling (BC); the $\mathrm{CC}$ is the worst case, $27.10 \%$ lower than BC on average, but fairly close (5.41\% difference in average) to the EHXC. So, it makes not a huge difference in terms of energy efficiency to have an indirect coupling by means of a coil inside the storage tank or an external brazed plate heat exchanger compared to the DWCC which is clearly the most efficient solution.

Finally, it is important to remark that the different climates have an influence on the efficiency of the system. The higher the ambient temperature the higher the system global efficiency, since a higher ambient temperature leads to less heat losses through the storage tank and a higher temperature inlet of the secondary fluid in the evaporator with a consequent lower compressor consumption. Thus, the SPF4 results for the warmer season are higher than those of the cold season, in the same vein than the best results are those for the warmer climate conditions, represented by Athens. The percentage reduction of SPF4 among the different types of coupling is similar, with little dependence on the climate, being $28.38 \%$ the maximum difference found with respect to the $\mathrm{BC}$ for the case of $\mathrm{CC}$ in Strasbourg during the summer working conditions. 


\subsection{Techno-economic and environmental results}

This section solves one of the main objectives of this work that is to conclude which is the optimal type of coupling from a techno-economic and environmental point of view. As the aim of the present work is to provide a general conclusion for all the regions of the Eurozone independently from the economic conditions of a certain country, an average interest rate, inflation rate and prices for the Eurozone were considered. Analogously, instead of considering just one specific country for the climate conditions, and according to the Energy Labelling normative [25], results are presented for 'warmer' (Athens), 'average' (Strasbourg) or 'colder' (Helsinki) climate conditions.

When comparing the HP cases with a conventional way of SHW production (immersion electric heater) a huge difference in energy consumption is appreciated, due to the greater energy efficiency of the HP. This difference is also appreciated when analyzing the annual costs of the system. The gas boiler case, which is also a conventional way of SHW production, has not been included in the techno-economic analysis due to the high $\mathrm{CO}_{2}$ emissions associated.

Table 5 presents the results of the economic indicators of the different types of coupling analysed, taking the immersion electric heater as the reference. The $\mathrm{CO}_{2}$ emission results, in tons of $\mathrm{CO}_{2}$ during the useful life of the facility (15 years), are also presented in Table 5.

\begin{tabular}{|c|c|c|c|c|c|}
\hline Climate & Case & PB & IRR & NPV & $\mathrm{CO}_{2} \mathrm{~T}$. \\
\hline \multirow{3}{*}{$\begin{array}{l}\text { Average } \\
\text { climate } \\
\text { conditions }\end{array}$} & $\mathrm{CC}$ & 11.08 & $6.35 \%$ & $1,919.59 €$ & 3.96 \\
\hline & EHXC & 10.37 & $7.28 \%$ & $2,669.81 €$ & 3.79 \\
\hline & DWCC & 9.60 & $8.40 \%$ & $3,399.21 €$ & 3.22 \\
\hline \multirow{3}{*}{$\begin{array}{l}\text { Warmer } \\
\text { climate } \\
\text { conditions }\end{array}$} & $\mathrm{CC}$ & 12.90 & $4.34 \%$ & $881.72 €$ & 2.94 \\
\hline & EHXC & 12.11 & $5.15 \%$ & $1,423.08 €$ & 2.88 \\
\hline & DWCC & 11.46 & $5.89 \%$ & $1,869.41 €$ & 2.49 \\
\hline \multirow{3}{*}{$\begin{array}{l}\text { Colder climate } \\
\text { conditions }\end{array}$} & CC & 11.12 & $6.30 \%$ & $1,891.50 €$ & 4.08 \\
\hline & EHXC & 10.32 & $7.34 \%$ & $2,704.98 €$ & 3.96 \\
\hline & DWCC & 9.47 & $8.60 \%$ & $3,530.56 €$ & 3.51 \\
\hline
\end{tabular}

Table 5. Economic indicators for the three average climates in Europe.

Analysing the results presented in Table 5, the major conclusion reached is that the DWCC is the best option from a techno-economic and environmental point of view for all the cases analysed. Since, independently on the climate conditions, it presents the lowest PB, the highest IRR and the highest NPV, as well as the lowest $\mathrm{CO}_{2}$ emissions. This makes the solution of a DWC as the optimal, having thus a big potential in the market and serving as a reason for the manufacturers to really opt for the DWC as the most convenient type of coupling for SHW production. Looking at the PB periods on Table 5, it is possible to conclude that there is still a need for improvement on HP technology. The PB periods are still quite high which is due to a high investment cost. A reduction of the HP technology investment cost will absolutely make HP technology more competitive in the market and lead to its wide use in Europe.

Although the relatively high cost of a HP is still a barrier in comparison with the cheapest technology (immersion electric heater), the investment on a HP proves to be profitable, and 
much more efficient, with a profit well above the consumer index price (CIP), with a PB under the useful life of the facility and with a NPV well above the investment costs.

\section{Conclusions}

This work is focused on the influence of the indirect coupling of a SHW system between an ASHP and the TES tank required by the EN 1717:2000. A TRNSYS integrated system model was built to assess the system energy performance, the cost-effectiveness and the environmental cost of three possible types of coupling: coil case (CC), external heat exchanger case (EHXC) and double wall condenser case (DWCC). The heat pump cases have been compared to the immersion electric heater option, being one of the conventional ways of SHW production.

The results show clearly the DWCC as the optimal indirect coupling between the heat pump and the thermal storage tank. This coupling option presents the highest efficiency (only $3.66 \%$ in average lower than the direct coupling case (BC)) and cost-effectiveness compared to an immersion electric heater (2933.06 $€$ higher in average), as well as the lowest $\mathrm{CO}_{2}$ emissions (only $3 \%$ in average higher than the $\mathrm{BC}$ ) among the cases simulated. Whereas the CC, being surprisingly the mostly used option nowadays, presents the worst efficiency ( $27.1 \%$ lower in average than the $\mathrm{BC}$ ) and cost-effectiveness (only $1564.27 €$ in average) and the highest $\mathrm{CO}_{2}$ emissions ( $21 \%$ higher in average than the $\mathrm{BC})$.

So, the DWC presents a big potential in the market, proving this alternative as technically and economically viable.

Although the relatively high cost of a HP is still a barrier in comparison with the cheapest technology (immersion electric heater), the investment on a HP proves to be profitable, and much more efficient.

\section{Acknowledgments}

The present work has been supported by the Generalitat Valenciana inside the program "Ayudas para la contratación de personal investigator en formación de carácter predoctoral (ACIF/2016/131)" and by the Ministerio de Educación, Cultura y Deporte inside the programme 'Formación de Profesorado Universitario (FPU15/03476)'

\section{References}

[1] "Energy Consumption Buildings." [Online]. Available: https://ec.europa.eu/energy/en/topics/energy-efficiency/buildings. [Accessed: 20-Jul2012].

[2] "Energy consumption in households." [Online]. Available: http://ec.europa.eu/eurostat/statisticsexplained/index.php/Energy_consumption_in_households. [Accessed: 20-Aug-2005].

[3] "Directive 2008/28/EC of the European Parliament and of the Council of 11 March 2008 on the promotion of the use of Energy from renewable sources." .

[4] H. Willem, Y. Lin, and A. Lekov, "Review of energy efficiency and system performance of residential heat pump water heaters," Energy Build., vol. 143, pp. 191-201, 2017.

[5] K. J. Chua, S. K. Chou, and W. M. Yang, "Advances in heat pump systems: A review," Appl. Energy, vol. 87, no. 12, pp. 3611-3624, 2010.

[6] A. Floss and S. Hofmann, "Optimized integration of storage tanks in heat pump systems 
and adapted control strategies," Energy Build., vol. 100, pp. 10-15, 2015.

[7] D. Fischer, T. R. Toral, K. B. Lindberg, B. Wille-Haussmann, and H. Madani, "Investigation of Thermal Storage Operation Strategies with Heat Pumps in German Multi Family Houses," Energy Procedia, vol. 58, no. 0, pp. 137-144, 2014.

[8] N. K. Ghaddar, "Stratified storage tank influence on performance of solar water heating system tested in Beirut," Renew. Energy, vol. 4, no. 8, pp. 911-925, Nov. 1994.

[9] Y. M. Han, R. Z. Wang, and Y. J. Dai, "Thermal stratification within the water tank," Renew. Sustain. Energy Rev., vol. 13, no. 5, pp. 1014-1026, 2009.

[10] M. Y. Haller, R. Haberl, I. Mojic, and E. Frank, "Hydraulic integration and control of heat pump and combi-storage: Same components, big differences," Energy Procedia, vol. 48, pp. 571-580, 2014.

[11] F. Liu, W. Zhu, Y. Cai, E. A. Groll, J. Ren, and Y. Lei, "Experimental performance study on a dual-mode CO 2 heat pump system with thermal storage," Appl. Therm. Eng., vol. 115, pp. 393-405, 2017.

[12] J. Glembin, C. Büttner, J. Steinweg, and G. Rockendorf, "Thermal storage tanks in high efficiency heat pump systems - Optimized installation and operation parameters," Energy Procedia, vol. 73, pp. 331-340, 2015.

[13] M. Tammaro, A. W. Mauro, C. Montagud, J. M. Corberán, and R. Mastrullo, "Hot sanitary water production with $\mathrm{CO} 2$ heat pumps: Effect of control strategy on system performance and stratification inside the storage tank," Appl. Therm. Eng., vol. 101, pp. 730-740, 2015.

[14] X. Jin, J. Maguire, D. Christensen, and N. Renewable, "Model Predictive Control of Heat Pump Water Heaters for Energy Efficiency Modeling of Heat Pump Water Heaters," in ACEEE Summer Study on Energy Efficiency in Buildings, 2014, pp. 133-145.

[15] "EN 1717:2000. Protection against pollution of potable water in water installations and general requirements of devices to prevent pollution by backflow." [Online]. Available: https://shop.bsigroup.com/ProductDetail/?pid=000000000030194313. [Accessed: 07Feb-2018].

[16] “TRNSYS." [Online]. Available: http://www.trnsys.com/. [Accessed: 02-Jul-2018].

[17] “Geothermal Technology for €conomic Cooling and Heating (Geot€ch)." [Online]. Available: http://www.geotech-project.eu/. [Accessed: 15-Feb-2018].

[18] M. X. Corberán JM, Cazorla A, Marchante J, Montagud C, "Modelling and energy analysis of a dual source heat pump system in an office building," in 16th International Conference on Sustainable Energy Technologies - SET 2017, 2017.

[19] J. M. Corberán, A. Cazorla-Marín, J. Marchante-Avellaneda, and C. Montagud, "Dual source heat pump, a high efficiency and cost-effective alternative for heating, cooling and DHW production," Int. J. Low-Carbon Technol., no. March, pp. 1-16, 2018.

[20] F. Ruiz-Calvo, C. Montagud, A. Cazorla-Marín, and J. M. Corberán, "Development and Experimental Validation of a TRNSYS Dynamic Tool for Design and Energy Optimization of Ground Source Heat Pump Systems," Energies, vol. 10, no. 10, p. 1510, 2017.

[21] M. J. C. J. M. Masip X., Cazorla-Marín A., Montagud C., "MODELING, ANALYSIS AND ENERGY OPTIMIZATION OF AN AIR SOURCE HEAT PUMP SYSTEM FOR SHW PRODUCTION," pp. 19-21, 2018. 
[22] R. Christensen, ALFA LAVAL Internal communication. 2017.

[23] J. M. Corberan et al., "'ART' A Computer Code To Assist The Design Of Refrigeration and A/C Equipment," Int. Refrig. Air Cond. Conf., no. 34, pp. 1-8, 2002.

[24] "Council Directive 98/83/EC of 3 November 1998 on the quality of water intended for human consumption." [Online]. Available: https://eur-lex.europa.eu/legalcontent/EN/TXT/?uri=CELEX\%3A31998L0083. [Accessed: 07-Feb-2018].

[25] "Commission Delegated Regulation (EU) No 811/2013 of 18 February 2013 supplementing Directive 2010/30/EU of the European Parliament and of the Council with regard to the energy labelling of space heaters, combination heaters, packages of space heater, temp." [Online]. Available: https://publications.europa.eu/en/publicationdetail/-/publication/a391612c-be78-40ee-96bc-acca563adc15/language-en. [Accessed: 07-Feb-2018].

[26] Peter Oostendorp, "SEasonal PErformance factor and MOnitoring," Intell. Energy Eur., 2012.

[27] “European Environment Agency (EEA)," 2018. [Online]. Available: https://www.eea.europa.eu/data-and-maps/daviz/co2-emission-intensity-3\#tabgooglechartid_chart_11_filters=\%7B\%22rowFilters\%22\%3A\%7B\%7D\%3B\%22columnFilt ers\%22\%3A\%7B\%22pre_config_ugeo\%22\%3A\%5B\%22European Union countries)\%22\%5D\%7D\%7D. [Accessed: 15-Feb-2018].

[28] "Eurostat," 2018. [Online]. Available: http://ec.europa.eu/eurostat/data/database. [Accessed: 15-Mar-2018].

[29] U. Jordan and K. Vajen, "DHWcalc: Program to generate Domestic Hot Water profiles with statistical means for user defined conditions," Proc. Sol. World Congr. 2005 Bringing Water to World, Incl. Proc. 34th ASES Annu. Conf. Proc. 30th Natl. Passiv. Sol. Conf., vol. 3, pp. 1525-1530, 2005.

[30] X. Masip, "Energy Optimization and Techno-Economic Assessment of an Air Source Heat Pump for Sanitary Hot Water Production," Universitat Politècnica de València, 2018.

\section{Appendix}

Table A1. Base Case investment costs.

\begin{tabular}{ccccrr}
\hline & & Base Case & & & \\
Component & Manufacturer & Features & Unitary price & Units & Price \\
\hline Tank & Mecalia & 200 I without coil & $3.70 €$ & $€ / \mathrm{I}$ & $740.00 €$ \\
HP & Geotech prototype & $8 \mathrm{~kW}$ & - & $€ / \mathrm{kW}$ & $4,000.00 €$ \\
Circulation pump & Wilo & YONOS PICO 25/1-8-130 & - & - & $138.75 €$ \\
Lines & - & - & $10 \%$ & - & $487.88 €$ \\
Loan interests & - & - & - & - & $772.05 €$ \\
TOTAL & - & - & - & - & $6,138.68 €$ \\
\hline
\end{tabular}

Table A2. Coil Case investment costs. 


\begin{tabular}{cccrrr} 
Component & Manufacturer & Features & Unitary price & Units & Price \\
\hline Tank with coil & Mecalia & 200 I- con coil & $3.90 €$ & $€ / I$ & $780.80 €$ \\
HP & Geotech prototype & $8 \mathrm{~kW}$ & - & $€ / \mathrm{kW}$ & $4,000.00 €$ \\
Circulation pump & Wilo & YONOS PICO 25/1-8-130 & - & - & $138.75 €$ \\
Lines & - & - & $10 \%$ & - & $491.96 €$ \\
Loan interests & - & - & - & - & $778.50 €$ \\
TOTAL & - & - & - & - & $6,190.01 €$ \\
\hline
\end{tabular}

Table A3. External Heat Exchanger Case investment costs.

\begin{tabular}{ccccrr}
\hline & & External Heat Exchanger Case & & \\
Component & Manufacturer & Features & Unitary price & Units & Price \\
\hline Tank & Mecalia & 200 I- sin coil & $3.70 €$ & $€ / I$ & $740.00 €$ \\
HP & Geotech prototype & $8 \mathrm{~kW}$ & - & $€ / \mathrm{kW}$ & $4,000.00 €$ \\
Circulation pump 1 & Wilo & YONOS PICO 25/1-8-130 & - & - & $138.75 €$ \\
Circulation pump 2 & Wilo & YONOS PICO 25/1-8-130 & - & - & $138.75 €$ \\
Intercambiador & SWEP & B16 22 placas & $18.43 €$ & $€ /$ placa & $405.37 €$ \\
Lines & - & - & $10 \%$ & - & $501.75 €$ \\
Loan interests & - & - & - & - & $858.15 €$ \\
TOTAL & - & - & - & - & $6,782.77 €$ \\
\hline
\end{tabular}

Table A4. Double Wall Condenser Case investment costs.

\begin{tabular}{|c|c|c|c|c|c|}
\hline \multicolumn{6}{|c|}{ Double Wall Condenser Case } \\
\hline Component & Manufacturer & Features & Unitary price & Units & Price \\
\hline Tank & Mecalia & 200 I- sin coil & $3.70 €$ & $€ / I$ & $740.00 €$ \\
\hline $\mathrm{HP}$ & Geotech prototype & $8 \mathrm{~kW}$ & - & $€ / k W$ & $4,000.00 €$ \\
\hline Circulation pump & Wilo & YONOS PICO 25/1-8-130 & - & - & $138.75 €$ \\
\hline DWC & Alfalaval & ACH18DW 18 placas & - & - & $611.71 €$ \\
\hline Lines & - & - & $0.10 €$ & - & $487.88 €$ \\
\hline Loan interests & - & - & - & - & $868.85 €$ \\
\hline TOTAL & - & - & - & - & $6,847.19 €$ \\
\hline
\end{tabular}

